\title{
InP nanowires quality control using SEM and Raman spectroscopy*
}

\author{
K. Grodecki ${ }^{1}$, E. DumiszewsKa ${ }^{2, \dagger}$, M. RomanieC ${ }^{2}$, W. Strupinski ${ }^{2}$ \\ ${ }^{1}$ Military University of Technology, 2 Kaliskiego St., 00-908 Warsaw, Poland \\ ${ }^{2}$ Institute of Electronic Materials Technology, 133 Wolczynska Str., 01-919 Warsaw, Poland
}

\begin{abstract}
Three different types of samples of InP nanowires, i.e. undoped, doped with $\mathrm{Si}$ and doped with Te, were grown and measured using SEM and Raman spectroscopy. Scanning Electron Microscope (SEM) images showed differences in the length, homogeneity and curvature of the nanowires. The most homogenous wires, grown most perpendicular to the surface, were those Si doped. They were also the shortest. Raman spectroscopy showed that the nanowires doped with Si had the lowest Full Width at Half Maximum (FWHM) TO band, which suggests the highest crystal quality of these wires. For the wires doped with Te, which were the most inhomogeneous, a low energy acoustic band was also observed, which suggests the lowest crystal quality of these structures.
\end{abstract}

Keywords: Raman spectroscopy; nanowires; epitaxy; InP

(C) Wroclaw University of Technology.

\section{Introduction}

In recent years, nanowires have become a very important material for optoelectronic applications [1-5]. Nanowire-based solar cells hold great promise for third-generation photovoltaic and powering nanoscale devices [6, 7]. Third-generation photovoltaics based on nanowire arrays and radial p-n junctions will make solar cells cheaper and more efficient than the currently fabricated devices. The geometry of nanowire crystals favors elastic strain relaxation and hence great freedom in the design of new compositional multijunction solar cells grown on mismatched materials [8, 9]. The efficiencies of solar cells on InP have increased and have reached up to $13.8 \%$ [10]. In order to achieve solar cell arrays with even higher efficiency it is important to grow high-quality nanowires with a well-controlled length. There are several methods to grow InP nanowires on an InP substrate, including those with [11-13] and without gold catalysts [14-19]. Such nanowires are grown by many

*Thie paper was presented at XIII Seminar on Surfaces and Thin-Film-Structures, Szklarska Poręba, Poland, 2015.

†E-mail: ewa.dumiszewska@itme.edu.pl different techniques such as metal-organic chemical vapor deposition (MOCVD) [13, 20] or selective-area metal organic vapor phase epitaxy [21], molecular beam epitaxy (MBE) [22], pulsed laser deposition and chemical beam epitaxy [19] mainly on (1 11 1)B InP substrates.

There are several methods to measure nanowires, including SEM [18, 19, 23, 24], transmission electron microscopy (TEM) $[18,19,25,26]$, Raman spectroscopy [17, 27] and X-ray diffraction. SEM and Raman are nondestructive and quite fast measurement techniques. Raman spectroscopy was already used to measure InP nanowires; however, mostly to analyze strain in these structures [17]. In this paper it is shown that using Raman spectroscopy one can measure also the quality of grown nanowires based both on the TO and LO [17] band and low energy acoustic band [28].

\section{Experimental procedures}

All the growth processes were carried out in an AIX 200 metalorganic vapor phase epitaxy (MOVPE) reactor. We grew InP nanowires which 
were undoped (samples A) or doped either with silicon (samples B) or tellurium (samples C) on semi-insulating InP ( $\left.\begin{array}{lll}1 & 1 & 1\end{array}\right)$ substrates. Colloidal Au with a diameter of about 30 to $40 \mathrm{~nm}$ was used as a catalyst. The gold nanoparticles were prepared using the Turkevich method. A tetrachloroauric acid solution was heated to the boiling point and then a reducing and stabilizing agent solution (sodium citrate) was added. The resultant solution was again heated until its color changed. The pieces of the substrate (about $10 \times 10 \mathrm{~mm}$ ) were subsequently put into the solution and left there for the time between a few hours and about 48 hours. The density of the gold particles on the substrate surface was dependent on this particular time. Shortly after, the substrates were inserted into the reactor and the growth procedure started. Trimethylindium (TMIn) and phosphine (PH3) were used as source gases, diethyltellurium, (DETe) and silane $\left(\mathrm{SiH}_{4}\right)$ as doping gases, whereas hydrogen was a carrier gas. The reactor pressure was kept constant at $10^{4} \mathrm{~Pa}$. The partial pressures of the sources varied for the purpose of achieving InP nanowires doped with tellurium or silicon with different carrier concentration. The growth time was identical for both dopants. The nanowires were studied by Raman Spectroscopy and Scanning Electron Microscopy.

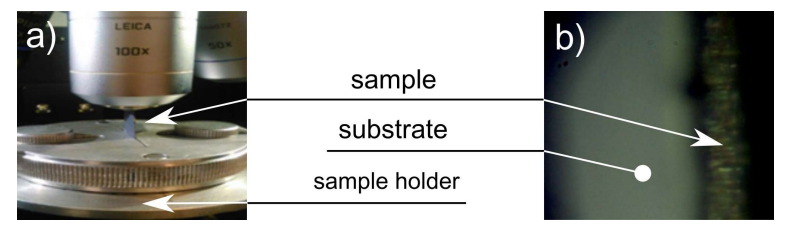

Fig. 1. The second method for measuring InP nanowires perpendicular to the measurement table: a) placement of the sample, b) view from the optical microscope.

Raman spectroscopy measurements were performed in a backscattering mode using $532 \mathrm{~nm}$ excitation laser and a $\times 100$ objective. Two methods were considered for analyzing the nanowires. In the first one, the wires were transferred onto a silicon or sapphire substrate and measured from the top of the sample. In the second method we measured the nanowires as if they were grown on InP but the substrate was located perpendicular to the measurement table. The first method we took into consideration allows one to measure almost every wire separately from other wires. However, in this case there is always an influence of the Raman signal from the substrate, which makes measurements more difficult and sometimes prevents the observation of some weak lines.

The second method allows the measurement of only these wires which are placed near the edge of the sample (Fig. 1).

In this case we can measure the majority of wires separately since there is no background from other materials and, in consequence, we can also compare the neighboring wires, which makes the measurement more complex.

In this study we used a field emission scanning electron microscope (FE-SEM) equipped with "in-lens" and Everhart-Thornley secondary electron detectors to obtain images of nanowires morphology in topographical contrast. Selected samples were examined in terms of height.

\section{Results and discussion}

Three series of samples were measured in this study: pure InP wires (samples A), wires doped with tellurium (samples B) and wires doped with silicon (samples C). In Fig. 2 SEM images of samples $\mathrm{A}, \mathrm{B}$ and $\mathrm{C}$ are presented.

In Fig. 2a one can see that InP nanowires without doping are quite high, but the growth is not stable since many of the wires are grown in a direction different than $\left\langle\begin{array}{lll}1 & 1 & 1\end{array}\right)$ and there is a significant dispersion of their length. InP nanowires doped with silicon (Fig. 2b) are much shorter than the undoped ones but they are also uniform and grow in one direction. Nanowires doped with $\mathrm{Te}$ are the longest but also have the highest inhomogeneity. Many of them grow in a direction other than $\left\langle\begin{array}{llll}1 & 1 & 1\end{array}\right\rangle$, since the change in their growth direction and the differences in length are the biggest.

In Fig. 3 typical Raman spectra of InP nanowires doped with silicon (red), tellurium (black) and undoped (blue) are presented. 


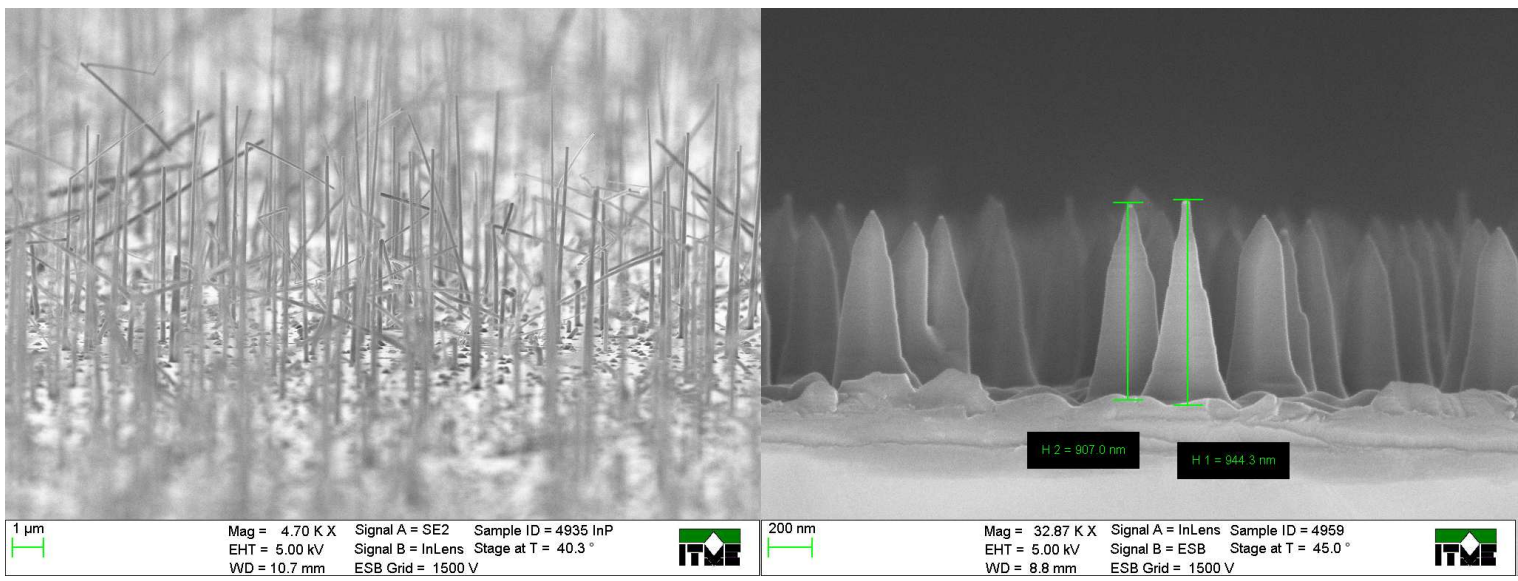

(a)

(b)

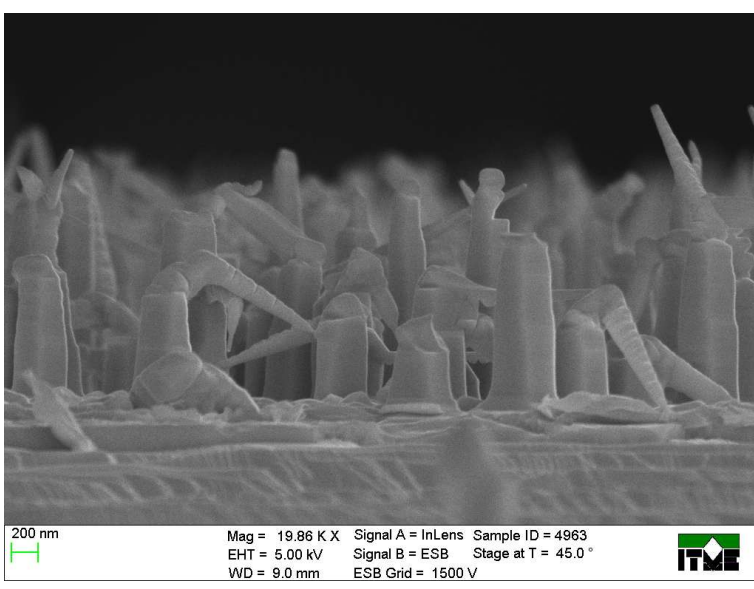

(c)

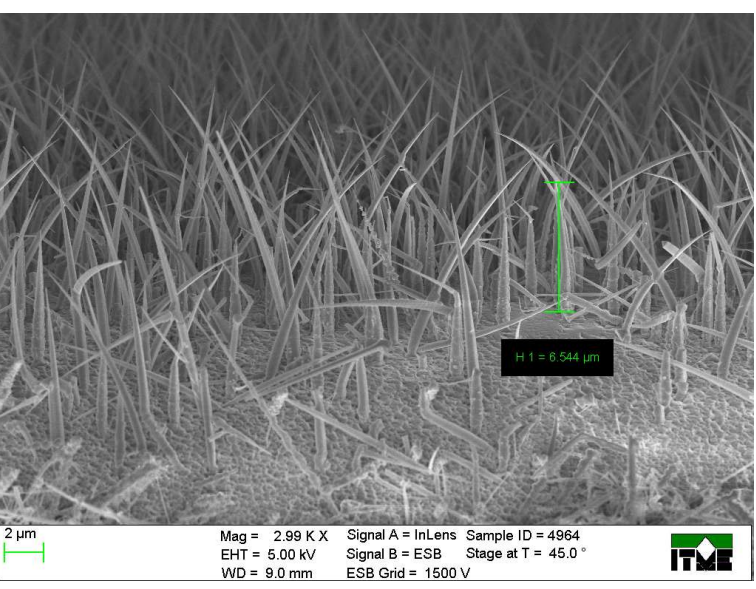

(d)

Fig. 2. SEM in-lens images of InP nanowires: (a) A - undoped, (b) B - doped with Si, (c), (d) C - doped with Te.

The Raman spectra of undoped nanowires and nanowires doped with Te have a broader TO band than in the case of nanowires doped with Si. Broadening of the TO band may stem from two different effects. In the first one [17], the effect comes from bending nanowires; in this case bending provides both blue and red shift of the TO band, which makes this band broader. The second interpretation is that FWHM of the TO and LO band is the signature of the crystal quality [28, 29]. In this experiment there has been no bending of wires so the broadening of TO band is more probably related to the crystal quality.

This suggests that samples in series $\mathrm{A}$ and $\mathrm{C}$ have a lower crystal quality than samples in series
B. To make a more detailed analysis, histograms of the FWHM TO band were done for samples A, B and C (Fig. 4).

The highest average Full Width at Half Maximum( FWHM) TO $\left(16 \mathrm{~cm}^{-1}\right)$ is observed for undoped wires, whereas for those doped with $\mathrm{Te}$ it is lower $\left(12 \mathrm{~cm}^{-1}\right)$, yet they are also very inhomogeneous. Both the average FWHM $\left(8 \mathrm{~cm}^{-1}\right)$ and the dispersion of FWHM are the lowest for Si nanowires. This suggests that the crystal quality is the highest for nanowires doped with Si. Moreover, it is in agreement with SEM measurements showing that $\mathrm{Si}$-doped wires are the smallest and the most uniform, which suggests that the crystal growth process is the most stable. 


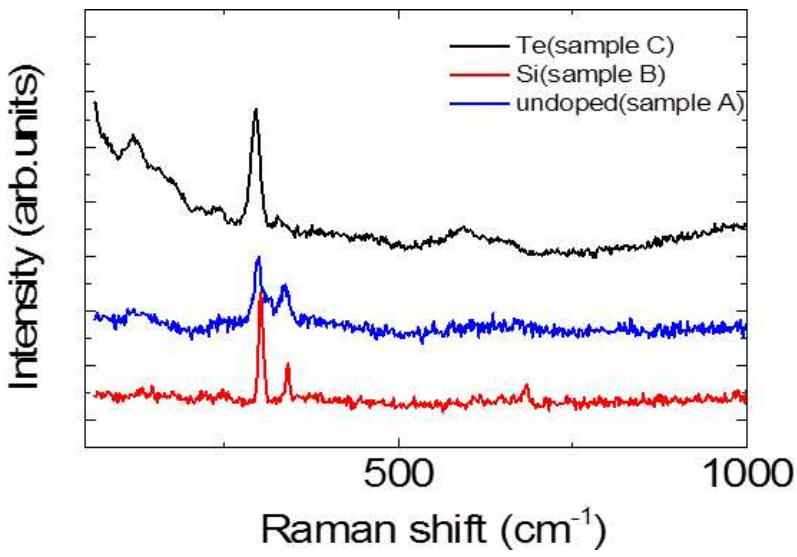

Fig. 3. Raman spectra of undoped InP nanowires (blue line), InP nanowires doped with $\mathrm{Si}$ (red line) and Te (black line).

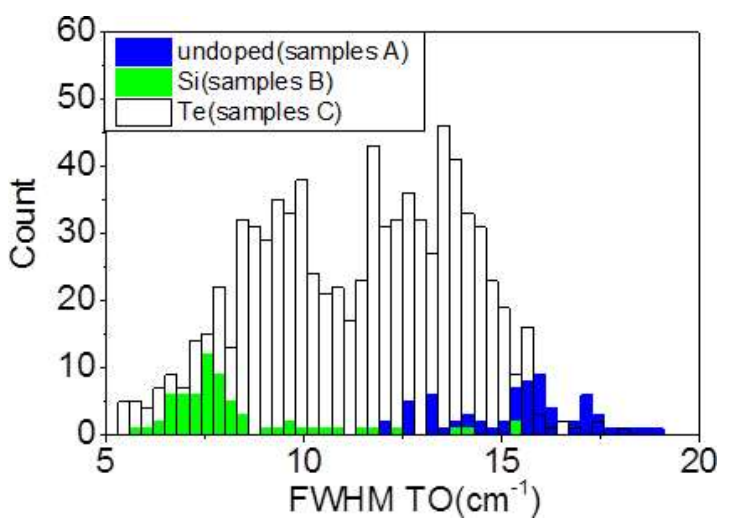

Fig. 4. Histogram of the FWHM TO band for undoped InP nanowires (blue color), InP nanowires doped with $\mathrm{Si}$ (green color) and Te (white color).

In Fig. 3 for sample $\mathrm{C}$ one can also see an additional signal below the TO band. These lines do not exist in a good-quality InP crystal. Three other spectra for this sample are presented in Fig. 5. The additional bands (marked as 1, 2, 3, 4, 5) are more regular for red spectrum and broader for black spectrum, thus making the background higher. The presence of additional bands cannot be accounted for as a result of stacking faults because each of these layers consists of a good-quality crystal. The existence of an amorphous-like material, similar to implanted InP can be treated as a possible explanation [29]. It is in agreement with the results of our previous observation of Te-doped nanowires having a very diverse quality. Probably some

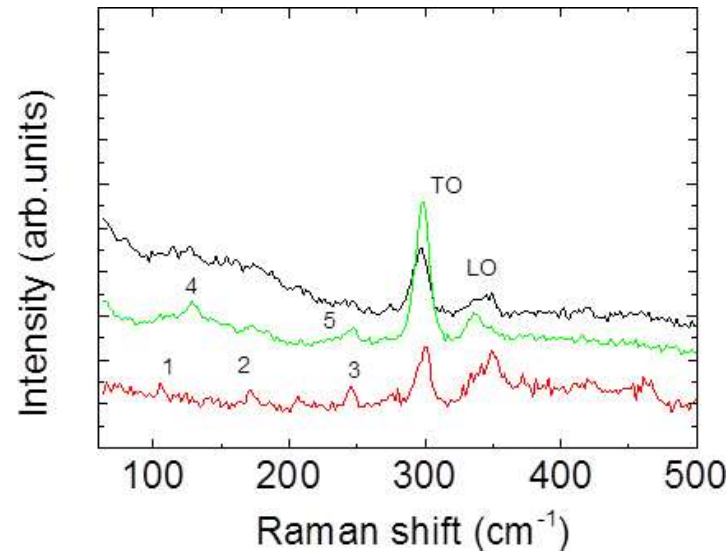

Fig. 5. Raman spectra for InP nanowires doped with Te. The presented spectra were chosen in such a way so as to get the highest lines below the TO band.

of the wires are growing so fast that in some places InP crystal is not properly built.

\section{Conclusions}

In summary, we measured three types of InP nanowires: undoped, doped with silicon and doped with tellurium. The estimation of their length, shape and homogeneity by SEM showed that the nanowires doped with silicon have the best parameters, probably because of the slowest growth rate. Raman spectroscopy showed that the FWHM TO band for the nanowires doped with silicon is smaller than for the other nanowires, which confirms the highest crystal quality of these wires.

In addition, we discovered several Raman bands below the TO mode for the nanowires doped with tellurium. The additional bands may stem from the local amorphous-like structure of the measured material. This confirms a low crystal quality of some of the nanowires doped with tellurium.

Our experiment showed that tellurium has an influence on the growth mode of nanowires. The nanowires doped with tellurium have the worst crystal quality.

\section{References}

[1] Duan X., Huang Y., Agarwal R., Lieber C., Nature 421 (2003), 241. 
[2] SAMUelson L., BJÖRK M., DepPert K., LARSSon M., Ohlsson B., Panev N., Persson A., Sköld N., Thelander C., Wallenberg L., Physica E 21 (2004), 560.

[3] Yan R., Gargas D.,Yang P., Nat. Photonics 3 (2009), 569.

[4] BorströM M., Wallentin J., Heurlin M., FÄlt S., Wickert P., LEENE J., MAGNuSSON M.H., DepPert K., SAmuelson L., IEEE J. Sel. Top. Quant. Electron. 17 (2011), 1050.

[5] Tomioka K., Yoshimura M., Fukui T., Nature 488 (2012), 189.

[6] Kayes B., Atwater H., Lewis N., J. Appl. Phys. 97 (2005), 114302.

[7] Kempa T., Cahoon J., Kim S., Day R., Bell D., Park H., Lieber C., Proc. Natl. Acad. Sci. USA 109, 1407 (2012).

[8] Chuang L., Moewe M., Chase C., Kobayashi N., Chang-Hasnain C., Crankshaw S., Appl. Phys. Lett. 90 (2007), 043115.

[9] Glas F., Phys. Rev. B 74 (2006), 121302.

[10] Wallentin J., Anttu N., Asoli D., Huffman M., Aberg I., Magnusson M., Siefer G., Fuss-KaIluWEIT P., DimRoth F., WitzigmanN B., Xu H., SAmuelson L., Deppert K., BorgStröm M., Science 339 (2013), 1057.

[11] Mĺrtensson T., Carlberg P., Borgström M., Montelius L., Seifert W., Samuelson L., Nano Lett. 4 (2004), 699.

[12] Gudiksen M., Wang J., Lieber C., J. Phys. Chem. B 105 (2001), 4062.

[13] Dick K.A., Deppert K., KARlsSon L.S., WAllenBerg L.R., Samuelson L., Seifert W., Adv. Funct. Mater. 15 (2005), 1603.

[14] Gao L., Woo R.L., Liang B., Pozuelo M., Prikhodko S., JaCKSON M., Goel N., Hudait M.K., HuffaKer D.L., GoORSKY M.S , KoDAMBAK A. S., HiCKS R.F., Nano Lett. 9 (2009), 2223.

[15] Kelrich A., Dubrovskit V.G., Calahorra Y., COHEN S., RitTer D., Nanotechnology 26 (2015), 085303 .
[16] Ren P., Xu, J. Wang Y., Zhuang X., Zhang Q. Zhou H., Wan Q., Shan Z., ZhU, X. Pan A., Phys. Status Solidi n/a (2013).

[17] Chen J., Conache G., Pistol M.-E., Gray, S.M., BorgStröm M.T., XU H., XU H.Q., SAMUELSON L., HÅKANSON U., Nano Lett. 10 (2010), 1280.

[18] Fanfair D.D., Korgel B.A., Cryst. Growth Des. 5 (2005), 1971.

[19] Hunia S. B., Kawamura T., Fujikawa S., NAKASHIMA H., FURUKAWA K., TORIMITSU K., Watanabe Y., Thin Solid Films 464-465 (2004), 244.

[20] Paiman S., Gao Q., Tan H.H., Jagadish C., PeMASIRI K., MONTAZERI M., JACKSON H.E., SMITH L.M., YARrison-Rice J.M., Zhang X., Zou J., Nanotechnology 20 (2009), 225606.

[21] Goto H., Nosaki K., Tomioka K., Hara S., Hiruma K., Мотоhisa J., Fukui T., Appl. Phys. Express 2 (2009), 035004.

[22] LiU J., Cai S., Jin G., Thomas S., Wang K., J. Cryst. Growth 200 (1999), 106.

[23] Maeda S., Tomioka K., Hara S., Motohisa J., Jpn. J. Appl. Phys. 51 (2012), 02BN03.

[24] Watanabe Y., Hibino H., Bhunia S., Tateno K., SEKIGUCHI T., Physica E 24 (2004), 133.

[25] Novotny C.J., YU P.K.L., Appl. Phys. Lett. 87 (2005), 203111.

[26] Wallentin J., EK M., WallenberG L.R., SAMUElson L., DepPert K., Borgström M.T., Nano Lett. 10 (2010), 4807.

[27] Yu S., Miao G., Jin Y., Zhang L., Song H., Jiang H., Li Z., Li , D., Sun X., Physica E 42 (2010), 1540.

[28] Yu S.J., Asahi H., Emura S., Sumida H., Gonda S., Tanoue H., J. Appl. Phys. 66 (1989), 856.

[29] RaO C.S.R., Sundaram S., Schmidt R.L., CoMAS J., J. Appl. Phys. 54 (1983), 1808.

Received 2016-04-19 Accepted 2016-10-13 